\section{APLS Receives Grant}

The Association for Politics and the Life Sciences is pleased to announce that it has been awarded a major grant from the Lilly Endowment, Inc. The purpose of the grant is to disseminate information about the work of the association, promote the circulation of the journal, and begin the process of producing curriculum guides in biopolitics and the public policy aspects of biotechnology. The grant period extends from May 1984 to May 1987.

\section{A Word of Appreciation}

We would like to thank the following people for their help in reviewing manuscripts submitted to Politics and the Life Sciences during the past year.

Larry Arnhart

Carol Barner-Barry

David Beam

Peter Corning

James C. Davies

Murray Edelman

Mark Emmert

Jenefer Giannasi

Gary Glenn

Samuel M. Hines, Jr.

Fred Kort

Milton Lodge

Joseph Losco

Claude Phillips

Glendon Schubert

James Schubert

John C. Wahlke

Meredith Watts
Manfred Wenner

Elliott White

Herbert Wilcox

Raymond Zilinskas

\section{New Benefit to APLS Members}

APLS members can now take advantage of a 10 percent discount on a new subscription to Ethology and Sociobiology. This offer will be in effect until December 31, 1984. Write directly to the journal at Elsevier Science Publishing Company, 52 Vanderbilt Avenue, New York, N.Y. 10017.

\section{Call for Papers}

The Research Committee on Biology and Politics is organizing two panel sessions at the forthcoming IPSA World Congress to be held in Paris, July 15-20, 1985. For these two sessions, we are permitted a total of six papers.

On behalf of the committee, I am inviting proposals for panel papers. We hope that most, though not necessarily all, of the papers presented will be empirical in nature and will report actual research findings. Proposals should be brief (preferably no more than two pages) and should indicate hypotheses, type of inquiry proposed, and, if practicable, expected nature of research findings. Proposals should be forwarded to me, for review by the committee, no later than October 1, 1984. Send them to: Albert Somit, Office of the President, Southern Illinois University at Carbondale, 116 Anthony Hall, Carbondale, IL 62901.

- Albert Somit

\section{European \\ Sociobiological Society}

The semi-annual meeting of the European Sociobiological Society was held in Arnhem, The Netherlands, July 7-8, 1984. Part of the meeting was devoted to the ethological studies of the free-ranging chimpanzee colony being conducted at the Arnhem Zoo.

The next meeting of the society will be held in December 1984 in Oxford, England. The theme of the meeting will be "In-group/Out-group: What are the Biological Bases of Xenophobia, Nationalism, and Racism?"

For information about membership and the society, contact Dr. Jan Wind, Institute of Human Genetics, Free University, P.O. Box 7161, 1007 MC Amsterdam, The Netherlands.

\section{International Technology Network}

Sheldon Krimsky of Tufts University is the coordinator for the International Network of the Social Impacts of Biotechnology (INSIB). He is in the

POLITICS AND THE LIFE SCIENCES, Vol. 3, No. 1, August 1984. ISSN 0730-9384. ๑ 1984 by The Association for Politics and the Life Sciences. 
process of developing a format and choosing subject matter for the next INSIB resource directory. The directory will include: (1) the names and addresses of researchers and science writers who actively examine the social dimensions of biotechnology; (2) current research projects; (3) up to three citations of recent published reports, studies, or books for each listed individual; and (4) an annotated bibliography of significant publications and studies between 1982 and 1984 other than those cited under the individual names listed in the directory.

If you would like to be listed in the directory or would like to receive a copy of it, contact Dr. Krimsky at the Department of Urban and Environmental Policy, Tufts University, Medford Massachusetts 02155.

\section{Call for Manuscripts}

The Michigan Quarterly Review, the cultural and literary journal of The University of Michigan, invites manuscripts for its fifth special issue, to be titled Science and the Human Image.

This collection will consider recent developments in the sciences which influence the perceptions that human beings have of themselves as creatures and as participants in society and the cosmos. The future of "human nature" will be addressed.
The Michigan Quarterly Review is geared to a general readership. A payment rate for contributions is currently being established. The submission deadline is September 1984. Send essays, interviews, memoirs, fiction, and poetry to: Editor, Science and the Human Image, Michigan Quarterly Review, 3032 Rackham Building, Ann Arbor, Michigan 48109.

\section{Environmental Impact Assessment Review}

The Review is a quarterly publication for planners, engineers, scientists, and administrators involved in the practice of environmental impact assessment. The journal encourages the submission of the following types of manuscripts: reflections on current practice; approaches to solving technical problems; case studies of innovative practice; theoretical analyses; research summaries; and news of agency and organization activities. For more information contact Lawrence E. Suss kind, Senior Editor, Department of Urban Studies and Planning, Massachusetts Institute of Technology, Cambridge, Mass. 02139.

\section{Space Policy}

Butterworth Scientific Limited will begin publishing a new quarterly journal, Space Policy, in February 1985. The publication will focus on the industrial, economic, political, legal, and social aspects of activities and development in outer space. It will also-report on military and strategic aspects of space development as well astheir implications for international relations. In addition to articles, the journal will carry book reviews, reports on conferences, and it will monitor new developments in technology.

For information about subscriptions and submissions, contact Dr. David Green, Butterworth Scientific Limited, P.O. Box 63, Westbury House, Bury Street, Guildford, Surrey GU2 5BH, United Kingdom.

\section{Meetings of Interest}

American Psychological Association

August 24-28, 1984

Toronto, Ontario, Canada

Ecological Society of America

August 5-7, 1984

Fort Collins, Colorado

Genetics Society of America

August 12-15, 1984

Vancouver, British Columbia,

Canada

History of Science Society

December 27-29, 1984

Chicago, Illinois

Population Association of America

March 28-30, 1985

Boston, Massachusetts 